\title{
Coccidiosis in the European badger (Meles meles) from England, an epidemiological study
}

\author{
M. A. ANWAR ${ }^{1 *}$, C. NEWMAN ${ }^{2}$, D. W. MACDONALD ${ }^{2}$, M. E. J. WOOLHOUSE ${ }^{3}$ and \\ D. W. KELL Y ${ }^{1}$ \\ ${ }^{1}$ Department of Zoology, University of Oxford, South Parks Road, Oxford OX1 3PS, UK \\ ${ }^{2}$ Wildlife Conservation Research Unit, Department of Zoology, University of Oxford, South Parks Road, \\ Oxford OX1 3PS, UK \\ ${ }^{3}$ Centre for Tropical Veterinary Medicine, University of Edinburgh, Roslin, Midlothian EH25 9RG, UK
}

(Received 6 September 1999; revised 4 October 1999; accepted 4 October 1999)

\section{SUMMARY}

In total 445 faecal samples were collected from 259 European badgers (Meles meles) in Wytham Woods, Oxfordshire, UK (462080). Microscopical examination revealed infection with 2 species of coccidia Eimeria melis and Isospora melis. From the initial examination of each animal, point prevalence rates of 0.44 and 0.35 were calculated for Eimeria and Isospora respectively. The intensity of infection was significantly greater for Eimeria than Isopora and the distribution of intensities was highly skewed for both species, with a few individuals shedding the majority of oocysts. Incidence and recovery rates for both coccidia species were calculated from longitudinal data collected at 3-monthly intervals from a subset of the adult badger population, and the predicted prevalence rates based on these were similar to the point prevalence rates. This suggests little, if any, parasite-induced mortality in the adult population. In contrast, there was a marked and significant reduction in the point prevalence and intensity of infection with Eimeria from cub to adult badger suggesting a degree of acquired immunity to Eimeria melis on initial exposure and/or that there is significant Eimeria-associated mortality in the cub population. No such relationship was found for Isospora infection. In those adult badgers with co-infections there was a direct relationship between the intensity of Eimeria and Isospora. The taxonomic status of these parasites suggests a heteroxenous life-cycle for I. melis, and direct transmission of E. melis. However, the greater than expected prevalence of co-infection is consistent with a common source of infection, such as communal latrines.

Key words: Eimeria melis, Isospora melis, prevalence, mortality.

\section{INTRODUCTION}

The first report on coccidia in the European badger (Meles meles) was by Kotlan \& Pospesch (1933) who reported Eimeria melis as a new species and a second diplosporid coccidia which resembled Lucetina rivolta $($ Lucetina $=$ Isospora). Later, Pellérdy (1955) named this latter parasite Isospora melis. Kamiya \& Suzuki (1975) reported coccidia oocysts, and macrogametocytes and microgametocytes found in the jejunal mucosa of a badger in Japan. They gave the size of oocysts, but they were unable to identify this parasite beyond mentioning that 'the coccidia parasite in this study probably belongs to genus Eimeria'.

Most of what we know of the epidemiology of coccidia is limited to studies of domesticated animals such as cattle (e.g. Taylor \& Catchpole, 1994) and poultry (e.g. Henken et al. 1992). In general, reports of coccidia in wild animals are limited to new geographical records (e.g. McAllister, Upton \& Trauth, 1994), descriptions of novel host-parasite

* Corresponding author: Department of Zoology, University of Oxford, South Parks Road, Oxford OX1 3PS, UK. Tel: +01865 271262. Fax: +01865 310447. E-mail: ali.anwar@zoo.ox.ac.uk combinations (e.g. McAllister et al. 1994), crude prevalence rates (e.g. Zarzara et al. 1990), and isolated records of pathogenicity (Oksanen, 1994). The present paper describes for the first time coccidia infections and the results of a longitudinal study of parasites in the European badger, Meles meles, with details of the epidemiology of these highly prevalent and potentially pathogenic endoparasites in the UK.

\section{MATERIALS AND METHODS}

\section{Study site and sampling}

Badgers (Meles meles) were studied in Wytham Woods, Oxfordshire, UK (462080). The study site occupies approximately $6 \mathrm{~km}^{2}$. Badger density is approximately 25 adults per $\mathrm{km}^{2}$ (Woodroffe \& Macdonald, 1995). Trapping and processing followed the methods described by Woodroffe \& Macdonald (1995). Badgers were caught between May 1996 and August 1997 using box traps placed near the burrow entrance and baited with peanuts. Upon capture, each badger was anaesthetized by intramuscular injection of $15-20 \mathrm{mg} / \mathrm{kg}$ ketamine hydrochloride, sexed and classified as adult or cub. 
All animals were tattooed with a unique code number and released at the site of capture after full recovery from anaesthesia.

At the same time, faecal samples were collected from each animal by enema, and placed in separate vials containing $2.5 \%(\mathrm{w} / \mathrm{v})$ aqueous potassium dichromate, mixed thoroughly and stored at $4{ }^{\circ} \mathrm{C}$. Upon return to the laboratory, faecal suspensions were filtered to remove gross material, and an aliquot centrifuged at $730 \mathrm{~g}$ for $3 \mathrm{~min}$. The pellet was weighed, re-suspended in a saturated solution of common salt and screened for coccidia oocysts by microscopy following the Parker \& Duszynski (1986) method. The intensity of infection (recorded as oocysts per gram of pelletted faecal material) was determined directly. Where the concentration of oocysts was too great to be accurately enumerated in this way, a second faecal pellet was prepared using the McMaster technique (Davis, 1973).

Sporulation time was estimated in heavy infections. Unsporulated oocysts were allowed to sporulate at $25^{\circ} \mathrm{C} \pm 2{ }^{\circ} \mathrm{C}$ in a $15 \mathrm{~cm}$ Petri dish containing a layer of $2.5 \% \mathrm{~K}_{2} \mathrm{Cr}_{2} \mathrm{O}_{7}$. To estimate the sporulation time the sample was examined twice daily.

A morphological study was conducted on sporulated oocysts at $\times 1000$ magnification using oil immersion with a calibrated ocular micrometer. All measurements are in micrometers $(\mu \mathrm{m})$. Means \pm s.E. $(n=50)$ and showing size range in parentheses (Duszynski, Eastham \& Yates, 1982). The taxonomic characters of oocysts were studied as recommended by Duszynski \& Wilber (1997).

\section{Epidemiological analysis}

Infection status (presence/absence) and changes in status (changed/unchanged) were recorded as binary outcomes (1/0) and analysed in GLIM with binomial errors and the logit link function with a denominator of 1's (Crawley, 1993). Intensity of infection was log-transformed and treated as a continuous variable with normal errors. Model fitting began with a maximal model and parameters were deleted by a process of backward elimination to arrive at the minimum adequate model (Crawley, 1993).

\section{RESULTS}

\section{Morphometric analysis}

Isospora. Oocysts ovoidal, measuring $32 \cdot 8 \pm$ $0 \cdot 34 \times 26 \cdot 9 \pm 0 \cdot 19 \mu \mathrm{m} \quad(25 \cdot 6-37 \cdot 8 \mu \mathrm{m} \times 24-29 \cdot 6 \mu \mathrm{m})$, Length/width (L/W) Ratio 1.22 $\pm 0 \cdot 124(1 \cdot 10-1 \cdot 57)$. Oocyst wall thickness : $1 \cdot 8 \mu \mathrm{m}$; composed of 2 layers; outer layer smooth, no micropyle. No oocystic residuum or polar granule develops. Sporulation takes $72 \mathrm{~h}$. Sporocysts ellipsoidal and with no Stieda body. Sporocysts measured $21.5 \pm 0.166 \times 14 \pm$ $0 \cdot 12 \mu \mathrm{m} \quad(19-24 \mu \mathrm{m} \times 12-16.6 \mu \mathrm{m}), \quad$ L/W Ratio $1 \cdot 55 \pm 0.017(1 \cdot 33-1 \cdot 85)$. The sporozoites: $14 \cdot 2 \pm$ $1 \cdot 16 \times 4 \cdot 0 \pm 0 \cdot 17 \mu \mathrm{m}(10-20 \mu \mathrm{m} \times 3-5 \mu \mathrm{m})$, round at one end and tapered at the other end.

Eimeria. Oocysts ellipsoidal, measuring $20 \pm$ $0 \cdot 18 \times 15.7 \pm 0.02 \mu \mathrm{m} \quad(16-22.6 \mu \mathrm{m} \times 13-18.8 \mu \mathrm{m})$, $\mathrm{L} / \mathrm{W}$ Ratio $1 \cdot 28 \pm 0 \cdot 017(1 \cdot 12-1 \cdot 5)$. Oocyst wall about $1.2 \mu \mathrm{m}$ thick; composed of 2 layers; outer layer smooth, no micropyle. Oocyst residuum $(4 \cdot 2 \times 2 \cdot 0 \mu \mathrm{m})$ and small refractile polar body $(1.4 \times 0.4 \mu \mathrm{m})$ present. Sporulation time $72 \mathrm{~h}$. Sporocysts ovoidal, $11.9 \pm 0.018 \times 6.5 \pm 0.08 \mu \mathrm{m} \quad(10-$ $14.2 \mu \mathrm{m} \times 5-8.2 \mu \mathrm{m}) . \mathrm{L} / \mathrm{W}$ Ratio $1.83 \pm 0.026(1.55-$ $2 \cdot 4)$. Stieda body present. Sporozoite: $9 \cdot 0 \pm 0 \cdot 05 \times$ $3.24 \pm 0.025 \mu \mathrm{m}(8.0-9.2 \mu \mathrm{m} \times 2.8-3.6 \mu \mathrm{m})$. Refractile body, round at thick end, measuring $3.6 \mu \mathrm{m} \times$ $2 \cdot 0 \mu \mathrm{m}$.

\section{Epidemiological analysis}

In total 445 faecal samples were collected from 259 badgers during 1996 and 1997, in 4 three-monthly surveys.

\section{Cross-sectional estimates of prevalence}

In total 259 badgers were sampled at least once. Treating infection status at first sampling as a crosssectional survey of infection, an overall point prevalence rate of $0.44(115 / 259)$ and $0.35(91 / 259)$ can be calculated for Eimeria and Isospora respectively. Stratifying these results by age and sex, the point prevalence rate for Eimeria was found to be significantly higher in cubs than adults $\left(\chi_{1}^{2}=43.85\right.$; $P<0.001$ ), but the point prevalence rate of Isospora was constant with age $\left(\chi_{1}^{2}=1.93 ; P>0.05\right)$ (Table 1). There was no significant interaction between age and sex, for either Isospora $\left(\chi_{1}^{2}=0.87 ; P>0.05\right)$ or Eimeria infection $\left(\chi_{1}^{2}=0.8 ; P>0.05\right)$ : in other words, there is no detectable difference in the prevalence rate between males and females as adults and cubs.

Mixed infections of Isospora and Eimeria were common (Table 1), and overall greater than expected by chance $\left(\chi_{1}^{2}=4.66 ; P<0.05\right)$. When separated into component demographic groups, only male badgers (adult + cub) had mixed infections at greater than expected frequency $\left(\chi_{1}^{2}=4.41 ; P<0.05\right)$, but the trend was in the same direction for all badgers and statistically indistinguishable between groups.

\section{Longitudinal estimates of incidence, recovery and prevalence}

Only 5 cubs (2 female, 3 male) were sampled for coccidia more than once. However, the faeces of 110 
Table 1. Point prevalence of Eimeria melis and Isospora melis and mixed infections of the two from first survey $(n=259)$, stratified by age and sex

\begin{tabular}{lcccc}
\hline \hline & Male cub $(\%)$ & Female cub $(\%)$ & Male adult $(\%)$ & Female adult $(\%)$ \\
\hline Eimeria melis & $22(95 \cdot 6)$ & $23(88 \cdot 5)$ & $36(32 \cdot 7)$ & $34(34)$ \\
Isospora melis & $9(39)$ & $13(50)$ & $39(35 \cdot 5)$ & $30(30)$ \\
Mixed & $9(39)$ & $12(46)$ & $16(14 \cdot 5)$ & $14(14)$ \\
Uninfected & $1(4 \cdot 3)$ & $2(7 \cdot 7)$ & $51(46 \cdot 4)$ & $50(50)$ \\
Total & $23(100)$ & $26(100)$ & $110(100)$ & $100(100)$ \\
\hline
\end{tabular}

Table 2. Intensity of infection with Eimeria melis and Isospora melis (as oocysts per gram of faeces) from first survey $(n=259)$, stratified by age and sex

\begin{tabular}{llllll}
\hline \hline & \multicolumn{2}{c}{ Isospora melis } & \multicolumn{2}{c}{ Eimeria melis } \\
\cline { 2 - 3 } \cline { 5 - 6 } & Geom. mean & Range & & Geom. mean & Range \\
\hline Overall & $10 \cdot 4$ & $1-6804$ & 59 & $1-16157$ \\
Cub & $12 \cdot 6$ & $1-535$ & & $369 \cdot 8$ & $1-16157$ \\
Adult & $9 \cdot 8$ & $1-6804$ & & $18 \cdot 1$ & $1-570$ \\
Male & $8 \cdot 6$ & $1-549$ & & $67 \cdot 6$ & $1-10305$ \\
Female & $12 \cdot 3$ & $1-6804$ & & $51 \cdot 5$ & $1-16157$ \\
\hline \hline
\end{tabular}

adult badgers (57 female, 53 male) was examined at roughly 3 -monthly intervals up to a maximum of 4 times $(0,3,6$ and 9 months). From these data it is possible to make a crude estimate of the rate at which adult badgers acquire and recover from these infections.

\section{Three-monthly incidence rate}

The incidence rate of Eimeria and Isospora was assessed at a 3-monthly time-scale. Above this, insufficient badgers were sampled to give meaningful results. All sample series for which an individual badger was negative for one survey and then sampled in the following 3-monthly survey were included.

For Eimeria, a total of 100 series were taken from both males and females. Of these, 24\% (95\% CI 15.5-32.5) became positive on the second survey. The incidence rate by sex was $0 \cdot 18(0 \cdot 052-$ $0 \cdot 308)$ for females and $0 \cdot 29(0 \cdot 115-0 \cdot 463)$ for males, and there was therefore no significant difference between the sexes $\left(\chi_{1}^{2}=1.524, P>0.05\right)$.

Of 104 series for Isospora, $17 \%(16.9-21.7 \%)$ became positive on the second survey. By sex, the incidence rate was $0.23(0.02-0.49)$ for females and $0 \cdot 11(0 \cdot 01-0 \cdot 29)$ for males, again not significantly different $\left(F_{1,103}=0 \cdot 1688, P>0 \cdot 05\right)$. There was no significant difference in incidence between Isospora and Eimeria $\left(\chi_{1}^{2}=2.281, P>0 \cdot 05\right)$.

One of the assumptions of this analysis of incidence is that adult badgers do not acquire resistance with each bout of infection. One way of testing this is to compare the incidence rate in badgers which have recovered from infection with the overall incidence. Too few instances of this were available for statistical analysis, but the data are suggestive: $33 \%$ (3/9) of badgers became Eimeria positive within 3 months of recovering from an Eimeria infection; $25 \%(2 / 8)$ of badgers became Isospora positive within 3 months of recovering from an Isospora infection. These values are very close to the overall incidence rates of 0.24 and 0.17 for Eimeria and Isospora respectively, and the implication is that acquired immunity does not increase significantly in adult life.

\section{Three-monthly recovery rate}

The analysis of recovery rates followed the same protocol as incidence, but taking the series starting point to be a parasite-positive sample. For Eimeria, of 43 positive samples, $63 \%(49-77 \%)$ became negative on the second survey (i.e. 3 months later). The recovery rates for females $(0 \cdot 6 ; 0 \cdot 35-0 \cdot 85)$ and males $(0.64 ; 0.32-0.96)$ were not significantly different $\left(\chi_{1}^{2}=0 \cdot 1, P>0 \cdot 05\right)$.

For Isospora, of 39 positive samples, $74 \%(60-$ $88 \%$ ) became negative on the second survey. Again, the recovery rates of females $(0.76 ; 0.55-0.97)$ and males $(0.73 ; 0.46-1 \cdot 0)$ were not significantly different $\left(\chi_{1}^{2}=0.07, P>0.05\right)$. There was no demonstrable difference in recovery rate between Isospora and Eimeria $\left(\chi_{1}^{2}=1 \cdot 1, P>0 \cdot 05\right)$.

\section{Prevalence rate from incidence and duration of infection}

We have already estimated the point prevalence rates of Eimeria and Isospora from the initial survey 
(Table 1). We can also calculate the expected prevalence from the incidence and recovery rates through the relationship:

prevalence $=$ incidence $\times$ duration of infection

where the duration of infection is the reciprocal of the recovery rate. Obviously, this assumes that there is no mortality associated with infection; if there were, then those animals would be lost to the survey and therefore would not appear in the analysis, reducing the estimate of incidence and elevating the estimate of recovery, and compounding to create an underestimate of prevalence.

Calculating overall prevalence by Equation (1), our prevalence estimates for Eimeria $(0.24 \times 1 /$ $0.63=0.38)$ and Isospora $(0.17 \times 1 / 0.74=0.23)$ are similar to the directly observed point prevalence rates in adult badgers of 0.33 for both Eimeria and Isospora in adult badgers from the initial survey (Table 1). This is suggestive of little, if any, parasite-induced mortality in adults.

\section{Intensity of infection}

The frequency distribution of intensity of infection, measured as oocysts per gram of faeces, was extremely overdispersed for both Eimeria and Isospora (Table 2). Of those animals infected, the geometric mean intensity of infection was significantly greater for Eimeria than Isospora $\left(F_{1,205}=28.66, P<0.01\right)$.

Of those infected, the intensity of Eimeria infection decreased dramatically and significantly from cub to adult $\left(F_{1,112}=40 \cdot 6, P<0 \cdot 01\right)$, but there was no significant difference in intensity of infection between males and females $\left(F_{1,112}=1 \cdot 136, P>0 \cdot 05\right)$, nor was there any interaction between the two factors $\left(F_{1,112}=0.03, P>0.05\right) \quad($ Table 2$)$. The intensity of Isospora infection did not vary by age $\left(F_{1,88}=0.71, P>0.05\right)$, sex $\left(F_{1,88}=1 \cdot 24\right)$ or the interaction of the two $\left(F_{1,88}=1 \cdot 53, P>0.05\right)$ (Table 2).

For those animals with concurrent Isospora and Eimeria infections, intensity significantly and positively co-varies: in other words, when the intensity of one parasite is high, the other is also high $\left(F_{1,48}=4 \cdot 4, P<0 \cdot 05\right)$. Stratifying for age, this trend holds true for adult badgers $\left(F_{1,28}=4 \cdot 6, P<0 \cdot 05\right)$ but disappears in cubs $\left(F_{1,19}=0 \cdot 143, P>0 \cdot 05\right)$.

However, the intensity of infection with one parasite does not appear to be affected by the presence or absence of the other species. Thus, there is no significant change in Eimeria intensity when coinfected with Isospora $\left(F_{1,113}=0.75, P>0.05\right)$ or vice versa $\left(F_{1,89}=0 \cdot 01, P>0 \cdot 05\right)$.

Although only 5 badgers were sampled more than once for coccidia, there are recapture records for 19 animals first sampled for coccidia as cubs (including captures during trapping in 1998). The initial intensity of Eimeria infection was considerably lower in those cubs which were recaptured 6 months later (169 oocysts/g), compared with those which were not (518 oocysts/g); in fact, none of the latter group was seen greater than 1 month after initial capture. However, the difference is not significant $\left(\chi_{1}^{2}=2 \cdot 3\right.$, $P>0 \cdot 05)$. There was only a negligible difference in mean intensity of Isospora infection between recaptured and unrecaptured individuals $(10.7$ versus $10 \cdot 2$ oocysts $/ \mathrm{g})\left(\chi_{1}^{2}=0 \cdot 04, P \gg 0 \cdot 05\right)$.

\section{DISCUSSION}

\section{Taxonomy and morphometric analysis}

There have been only 3 previous reports of Isospora melis and Eimeria melis in badgers.

The first report on coccidia of the European badger (Meles meles) was by Kotlan \& Pospesch (1933) who reported 2 species: Eimeria melis as a new species with oocysts measuring $17-24 \mu \mathrm{m} \times 14$ $15 \mu \mathrm{m}$; and a diplosporid coccidia which resembled the cat coccidia Lucetina rivolta (Lucetina is a synonym of Isospora), with oocysts measuring 26$34 \times 20-27 \mu \mathrm{m}$. However, Kotlan \& Pospesch were not able to infect badgers with $L$. rivolta collected from cats and also could not infect cats with the putative Lucetina oocysts collected from badgers. Later, Pellérdy (1955) recovered the same Lucetinalike oocysts $(27-31 \mu \mathrm{m} \times 18-24 \mu \mathrm{m})$ from badgers and named the parasite as a new species, Isospora melis. Finally, Kamiya \& Suzuki (1975) reported coccidia oocysts measuring $20-21 \mu \mathrm{m} \times 14-17 \mu \mathrm{m}$, also macrogametocytes and microgametocytes found in the jejunal mucosa of a badger in Japan. They mentioned that 'the coccidia parasite in this study probably belongs to genus Eimeria', and this was therefore probably Eimeria melis.

We conclude that the species described in the present paper are those reported before as Eimeria melis and Isospora melis, based on the similarity of taxonomic characters with those previously reported. There is some variation in size between our measurements and those reported earlier. Size variation has been reported in other species of coccidia; the size of oocysts change not only in different individuals but also at different stages of infection (Joyner, 1982).

\section{Epidemiology}

It is sometimes assumed that an absence of coccidia oocysts in a faecal sample represents an absence of infection. Of course, it is possible that oocysts are present but at undetectable levels, as has been recorded in sheep and goats which discharge oocysts continuously at low numbers (Pellérdy, 1974). Indeed, the total absence of parasites is thought unlikely under conditions of continuous exposure to infection (Wakelin \& Apanius, 1997). Therefore 
what we term incidence may, at least in part, be the rate of recrudescence of an existing infection rather than a newly acquired infection. Similarly, what we call recovery (or immunity) may not be the elimination of parasites, but rather a degree of remission sufficient to reduce oocyst levels below a detectable threshold.

\section{Exposure to infection}

There is no evidence that the prevalence, and therefore the risk of infection with either Eimeria or Isospora, is different in males and females, either as cubs or adults. The inference is that both exposure and susceptibility to infection are constant between the sexes. Prevalence of Eimeria does decrease with age. However, the intensity of Eimeria infection also decreases, which, for such a notoriously ubiquitous microparasite as Eimeria, suggests a change in immune profile of the population from cub to adult (either acquired or through the death of innately susceptible individuals - see below), rather than change in exposure to parasites.

Eimeria species are known to be monoxenous (i.e. they have direct life-cycles), transmitted by the faecal-oral route. In contrast, some genera of Isospora complex are heteroxenous. Lindsay \& Blagburn (1994) reviewed mammalian Isospora and indicated that species which lack a Stieda body and are not sporulated when shed-which from our observations would therefore include Isospora melis - may be faculatively heteroxenous.

Although the badger is classified in the Carnivora (family Mustelidae), observations on their dietary habits reveal them to be generalist or opportunist feeders (Roper, 1994). According to Kruuk (1978), in Wytham and through much of the UK they feed predominantly on the earthworm Lumbricus terrestris, supplemented by other invertebrates, with rodents only rarely eaten. As $35 \%$ of badgers harboured Isospora infection, it is unlikely that the source of infection is vertebrate prey. Either badger isosporan infection is monoxenous - in this case they are not in the category suggested by Lindsey \& Blagburn (1994) - or it is likely that earthworms are transmitting the parasite. Against this hypothesis, non-vertebrate hosts of coccidia appear rare (Snyder et al. 1990).

However, the greater than expected co-incidence of Eimeria and Isospora infections suggests either that the risk factors for infection with one species overlap with those for the other, or that the presence of one directly increases the risk of acquiring the other (e.g. by immuno-compromising the host). The latter explanation is contradicted by the observation that a co-infection with one parasite does not correlate with an increase in intensity of the other. Yet the former explanation seems unlikely if the mode of transmission of Eimeria is monoxenous and of Isospora heteroxenous, and might indicate that Isospora is at least partly directly transmitted, like Eimeria, explaining the co-incidence by co-exposure, say in communal latrines.

\section{Mortality and immunity}

Wytham badgers are either acquiring and resolving Eimeria and Isospora infections, or relapsing and recovering from a single chronic infection, with high frequency. The result is a high point prevalence of both infections in the Wytham badger population. Indeed, in the cub population virtually all individuals were infected at first sampling, and it is reasonable to assume that all would be exposed to infection at some point.

The considerable reduction in both prevalence and intensity of Eimeria infection from cub to adult can be interpreted either as infection-associated mortality in those cubs with the highest intensities of infection, or the acquisition of immunity to infection leading to a reduction in the mean intensity of infection and the consequent loss of patent infection in some animals, or a combination of the two. Conversely, the prevalence and intensity of Isospora infection does not appear to change with age, and the mean intensity of Isospora infections was also considerably lower than that of Eimeria.

If re-appearance in traps could be treated as a measure of cub survival, then the much lower initial intensity of infection with Eimeria - but not Isospora-in those which survived to be trapped at least 6 months later suggests that Eimeria-and not Isospora - can cause death in the most susceptible of cubs. However, the sample size was small, and the observation is not significant.

In contrast, there is indirect evidence, from the comparison of the point prevalence rate with the prevalence rate estimated from incidence and recovery, to suggest that adult badgers do not suffer any significant mortality from Eimeria or Isospora infections. Neither do they appear to acquire significant additional immunity to infection at this age. This would be expected if either those badgers not competent to fight infection died before reaching maturity, and/or the level of acquired immunity asymptotes in adulthood to a maximum upon repeated or prolonged exposure to the parasite as is seen for other chronic endoparasitic infections (Cox, 1998). It is worth noting in this context that first exposure to Eimeria occurs very early in Wytham badgers: almost all cubs were found to have contracted infections, and any immunity may therefore develop very early in life.

We would like to thank all those involved in the field team and also 2 anonymous reviewers for their comments. Grants from the Peoples' Trust for Endangered Species, the Royal Society and NERC made this study possible. The work was performed under License PPL 30/12166. 


\section{REFERENCES}

COX, F. E. G. (1998). Control of coccidiosis: lessons from other sporozoa. International Fournal for Parasitology 28, 165-179.

CRAWLEY, M. J. (1993). Glim for Ecologists. Blackwell Scientific Publications, Oxford.

Davis, L. R. (1973). Techniques. In The Coccidia: Eimeria, Isospora, Toxoplasma, and Related Genera (ed. Hammond, D. M. \& Long, P. L.), pp. 411-458. University Park Press, Baltimore.

DUSZYNSKI, D. W. \& WILBER, P. G. (1997). A guideline for the preparation of species description in the Eimeriidae. Fournal of Parasitology 83, 333-336.

DUSZYNSKi, D. W., EASTHAM, G. \& YATES, T. L. (1982). Eimeria from jumping mice (Zapus spp.): a new species and genetic and geographic features of $Z$. hudsonius luteus. Fournal of Parasitology 68, 1146-1148.

henken, A. M., Goelma, J. P., Neijenhuis, F., VERTOMMEN, M. H., VAN DEN BOS, J. \& FRIS, C. (1992). Mulivariate epidemiological approach to coccidiosis in broilers. Poultry Science 71, 1849-1856.

JOYNER, L. P. (1982). Host and site specificity. In The Biology of the Coccidia, 2nd Edn (ed. Long, P. L.), pp. 35-62. Edward Arnold, London.

KAMiYA, H. \& SUZUKi, y. (1975). Parasite of the Japanese badger, Meles meles anakuma Temminck, especially on Isthmiophora melis (Schrank, 1788) Lühe, 1909.

Fapanese Fournal of Veterinary Research 23, 125-130.

Kotlan, A. \& POSPesch, L. (1933). Coccidial infections in the badger Meles taxus L. Parasitology 25, 102-107. KRUUK, H. (1978). Foraging and spatial organization of the European badger Meles meles L. Behavioral Ecology Sociobiology 4, 75-89.

LindSAY, D. S. \& BLAGBURN, B. L. (1994). Biology of mammalian Isospora. Parasitology Today 10, 214-220. MCALlister, C. T., UPTON, S. J. \& TRAUTH, S. E. (1994).
New host and geographic records for coccidia (Apicomplexa: Eimeriidae) from North American turtles. Fournal of Parasitology 80, 1045-1049.

oksanen, A. (1994). Mortality associated with renal coccidiosis in juvenile wild greylag geese (Anser anser anser). Fournal of Wildlife Diseases 30, 554-556.

PARKER, B. B. \& DUSZYNSKI, D. W. (1986). Coccidiosis of sandhill crane (Grus canadensis) wintering in New Mexico. Fournal of Wildlife Diseases 22, 25-35.

PELlÉRDY, L. (1955). Beiträge zur Kenntnis der Coccidien des Dachses (Meles taxus). Acta Veterinaria 5, 421-424.

Pellérdy, L. (1974). Coccidia and Coccidiosis, 2nd Edn. Akademiai Kiado, Budapest.

ROPER, T. J. (1994). The European badger Meles meles: food specialist or generalist? Fournal of Zoology (London) 234, 437-452.

SYNDER, D. E., SANDERSON, G. C., TOIVIO-KINNUCAN, M. \& Blagburn, B. L. (1990). Sarcocystis kirkpatriki n.sp. (Apicomplexa: Sarcocystidae) in muscles of raccoons (Procyon lotor) from Illinois. Fournal of Parasitology 76, 495-500.

TAYlor, M. A. \& CATChPole, J. (1994). Review article: Coccidiosis of domestic ruminants. Applied Parasitology 35, 73-86.

WAKELIN, D. \& APANIUS, v. (1997). Immune defense: genetic control. In Host-Parasite Evolution, General Principles and Avian Models (ed. Clayton, D. H. C. \& Moore, J.), pp. 30-58. Oxford University Press, Oxford.

WOOdRofFe, R. \& MACDONALd, D. W. (1995). Female/male competition in European badger Meles meles: effects on breeding success. Fournal of Animal Ecology 64, 12-20.

Zarzara, C., iluc, D., Marcoci, M. \& POpovici, A. (1990). Studies concerning the parasitic fauna in polar foxes, minks and polecats. Archiva Veterinaria Bucuresti 20, 65-87. 